\title{
DIAGNÓSTICO DE ENFERMAGEM PARA O TRANSPLANTE RENAL: RELATO DE CASO
}

\author{
Nursing diagnosis for kidney transplantation: case report
}

Maria Conceição da Costa Proença', Miriam de Abreu Almeida ${ }^{3}$, Fernanda Schnath ${ }^{3}$, Débora Hexsel Gonçalves H,2 $^{1,2}$

\begin{abstract}
RESUMO
Objetivo: A doença renal crônica é multicausal, progressiva e com elevada morbidade e letalidade, controlável, porém, incurável. Todavia, pode ser tratável de várias maneiras, como: tratamento conservador, diálise e transplante renal, que é o tratamento mais efetivo. A sistematização da assistência de enfermagem no Hospital de Clínicas de Porto Alegre segue o referencial das Necessidades Humanas Básicas e consiste nas etapas: coleta de dados (anamnese e exame físico), diagnóstico de enfermagem, prescrição e evolução de enfermagem. Diagnóstico de enfermagem é o julgamento clínico das respostas do indivíduo aos processos vitais ou aos problemas de saúde atuais ou potenciais, que fornece a base para a seleção das intervenções de enfermagem. O presente relato de caso busca relatar as etapas da sistematização da assistência de enfermagem, com ênfase nos diagnósticos de enfermagem obtidos nas fases pré e pós-operatória da cirurgia de transplante renal. Trata-se de um relato de caso sobre um paciente com doença renal crônica submetido a transplante renal com doador vivo. Os dados foram coletados a partir da anamnese, exame físico, evolução de enfermagem e exames laboratoriais, resultando na elaboração dos seguintes diagnósticos de enfermagem, segundo a metodologia da NANDA: Risco para Controle Ineficaz do Regime Terapêutico, Risco para Infecção, Integridade Tissular Prejudicada, Volume de Líquidos Excessivo, Proteção Ineficaz e Dor Aguda; e cuidados de enfermagem.
\end{abstract}

Descritores: Enfermagem, Diagnóstico de Enfermagem, Transplante Renal, Processos de Enfermagem.

Autores:

${ }^{1}$ Transplante Renal e Pancreático do Hospital de Clínicas de Porto Alegre

${ }^{2}$ Escola de Enfermagem da Universidade Federal do Rio Grande do Sul

${ }^{3}$ Serviço de Enfermagem Médico Cirúrgica do Hospital de Clínicas de Porto Alegre

Instituições:

Hospital de Clínicas de Porto Alegre e Escola de Enfermagem da Universidade Federal do Rio Grande do Sul - Porto Alegre, RS, Brasil

\section{Correspondência:}

Maria Conceição da Costa Proença

Rua Dona Laura 60 apto. 302

90430-090 - Bairro Rio Branco - Porto Alegre - RS

Tels: 555132229741 / 99711462 / 21018885

Email: mproenca@hcpa.ufrgs.br

Recebido em: 03.09 .2006
Aceito em: 19.12 .2006

\section{INTRODUÇÃO}

A doença renal crônica é multicausal (diabetes, hipertensão arterial sistêmica, glomerulonefrites, doença renal cística, nefrite intersticial, neuropatia obstrutiva, doenças vasculares do colágeno, doenças hereditárias e congênitas, desconhecida e outras), progressiva e com elevada morbidade e letalidade, controlável, mas incurável. ${ }^{1,2}$

Contudo, pode ser tratável de várias maneiras, como: tratamento conservador, que se dá através do uso de medicamentos, dieta, controle da pressão arterial, controle da glicemia e outros; diálise, que é um processo através do qual a composição de solutos de uma solução (sangue) é alterada pela exposição dessa solução a uma segunda (dialisato ou banho de diálise) através de uma membrana semipermeável. ${ }^{1,2}$

Porém, o tratamento mais efetivo para o paciente portador de insuficiência renal crônica é o transplante renal, que consiste em um procedimento cirúrgico no qual um rim normal de um doador é colocado no paciente (receptor) com doença renal crônica terminal. Atualmente, é possível a realização de transplante renal com doador falecido ou doador vivo relacionado. Conforme os aspectos legais, no transplante renal com doador vivo é permitida a doação de parente de até $4^{\circ}$ grau que seja maior de idade, que se manifeste espontaneamente, tendo compatibilidade sangüínea e imunológica com o receptor. ${ }^{3}$

A cirurgia do transplante renal é considerada de médio porte, sendo realizada mediante anestesia geral, em que o rim doado é colocado na fossa ilíaca direita ou esquerda. ${ }^{3}$ 
A Sistematização da Assistência de Enfermagem no Hospital de Clínicas de Porto Alegre (HCPA) segue o referencial das Necessidades Humanas Básicas (NHB) e consiste nas seguintes etapas: coleta de dados, realizada através da anamnese e exame físico; diagnóstico de enfermagem (DE); prescrição e evolução de enfermagem. Tais etapas constam na descrição deste relato de caso. ${ }^{4-6}$

Na operacionalização do processo de enfermagem, pode-se realizar a adaptação da Taxonomia I Revisada dos Diagnósticos de Enfermagem, proposto pela NANDA ${ }^{5}$, visto que o diagnóstico proposto por Horta consiste na identificação das Necessidades Humanas Básicas afetadas, e determinação pelo enfermeiro do grau de dependência do paciente para 0 atendimento dessas necessidades.

Diagnóstico de enfermagem conceitua-se como o julgamento clínico das respostas do indivíduo, da família ou da comunidade aos processos vitais ou aos problemas de saúde atuais ou potenciais, que fornece a base para a seleção das intervenções de enfermagem, para atingir resultados pelos quais o enfermeiro é responsável. ${ }^{8}$

A estrutura do diagnóstico de enfermagem compreende três componentes: o problema de saúde, os fatores etiológicos ou relacionados e as características definidoras (ou os grupos de sinais e sintomas). O problema é o estado de saúde relacionado, manifestado pelo indivíduo, família ou comunidade, que engloba variáveis bio-psico-sócio-espirituais. Os fatores etiológicos ou relacionados podem ser comportamentos do paciente e/ou elementos do ambiente, que são a base para intervenções para resolver o problema.

As características definidoras são dados objetivos e subjetivos, sinais e sintomas que indicam a presença do diagnóstico de enfermagem. ${ }^{8}$

Os estudos de caso, as análises e os comentários associados são recursos utilizados para aprender sobre as complexidades do diagnóstico das respostas humanas, assim como as estratégias de pensamento para lidar com essas complexidades. ${ }^{9}$ Uma vez identificada a área do problema e o caso ou casos a serem estudados, o pesquisador deve desenvolver a coleta de dados através de questionários, entrevistas, planos de observações, planos de avaliação, medidas psicológicas, ou até associar várias dessas técnicas. Realizada a coleta de dados, torna-se necessário analisar ou interpretar os mesmos. Alguns estudos de caso exigem intervenções e acompanhamento das conseqüências das intervenções no indivíduo. ${ }^{10}$

Os DE podem ser reais ou de risco. O diagnóstico real descreve um estado de saúde que foi validado pela(o) enfermeira(o), devido à presença de determinadas características definidoras e possui três partes: definição, características definidoras e fator relacionado. Os diagnósticos de risco descrevem a vulnerabilidade de um determinado indivíduo ou grupo desenvolver determinados problemas de saúde e consiste de duas partes: definição e fatores de risco. ${ }^{4}$

O presente artigo tem por objetivo apresentar um estudo de caso de um paciente portador de Doença Renal Crônica (DRC) submetido a transplante renal, com ênfase na avaliação dos diagnósticos de enfermagem, colaborando para uma assistência de enfermagem eficiente e atualização do sistema informatizado.

\section{MÉTODOS}

Trata-se de um relato de caso sobre um paciente com DRC submetido a transplante renal de doador vivo. Os dados foram coletados a partir dos registros no prontuário no intervalo de tempo entre os períodos pré e o pós-operatório (de 15 de setembro de 2006 a 17 de novembro de 2006). As informações relevantes constavam na anamnese, exame físico, evolução de enfermagem e exames laboratoriais.

A análise dos dados permitiu a elaboração dos DE reais e de risco, aplicáveis para paciente submetido a transplante renal. $\mathrm{O}$ direito à privacidade fica assegurado, uma vez que os dados coletados foram trabalhados sem a identificação do sujeito, preservando-se o anonimato e assegurando-se o caráter confidencial das informações e a utilização das mesmas somente para fins deste estudo. ${ }^{11}$ Os autores apresentaram o termo de consentimento, que foi assinado pelo paciente.

\section{RELATO DE CASO}

Paciente masculino, 26 anos, cor morena, casado, natural e procedente de Porto Alegre, grupo sangüíneo B positivo, nega transfusões de sangue e alergias. Relata história de drogadição e etilismo no passado, apresentando como patologias prévias: Hipertensão Arterial Sistêmica, Doença Renal Crônica terminal por infecção do trato urinário de repetição e encontra-se em programa de hemodiálise há dez meses no HCPA. Exames laboratoriais précirurgia: creatinina: $10,5 \mathrm{mg} / \mathrm{dl}$, uréia: $147 \mathrm{mg} / \mathrm{dl}$, potássio: 4,7 $\mathrm{mEq} / \mathrm{L}$, glicose: $82 \mathrm{mg} / \mathrm{dl}$, colesterol total: $129 \mathrm{mg} / \mathrm{dl}$, triglicerídeos: $185 \mathrm{mg} / \mathrm{dl}$, hematócrito $35,02 \%$, hemoglobina $12,5 \%$, HCV: negativo, HbsAg: negativo, HIV: negativo, toxoplasmose: negativo, VDRL: negativo e imunofluorescência para chagas: positivo.

No segundo dia pós-operatório, referiu dor no local da cirurgia ao movimentar-se e dúvidas sobre o procedimento cirúrgico que foi realizado e acompanhamento após alta hospitalar. Apresentava-se lúcido, orientado e com mucosas descoradas. Pouco comunicativo, com faces de dor, hidratado, alimentando-se bem. Pressão arterial: 160/100 mmHg e demais sinais vitais estáveis. Foi mantido acesso venoso periférico em membro superior esquerdo com soro fisiológico $0,9 \%$, fístula arterio-venosa em membro superior direito com pulso e frêmito adequados. Peso ideal: $73,5 \mathrm{~kg}$ e peso atual: $78,2 \mathrm{~kg}$. Ferida operatória em fossa ilíaca direita com curativo limpo. Sonda vesical de demora, drenando urina clara com volume $2950 \mathrm{ml}$ em 24hs. Membros inferiores perfundidos e com discreto edema.

\section{RESULTADOS E DISCUSSÃO}

Os Diagnósticos de Enfermagem são julgamentos clínicos sobre as respostas do indivíduo, da família ou da comunidade aos problemas de saúde / processos de vida vigentes ou potenciais. Os DE proporcionam a base para a escolha de intervenções de enfermagem que visam a obtenção de resultados pelos quais a enfermeira é responsável. ${ }^{5}$ Foram levantados neste estudo dois diagnósticos de risco e quatro reais, classificados conforme a teoria das Necessidades Humanas Básicas de Horta $^{6}$ e Taxonomia de NANDA ${ }^{5}$. As intervenções de enfermagem são descritas com base no sistema informatizado do HCPA, Manual de Orientações ${ }^{4}$ e NIC12.

\section{Diagnóstico de Enfermagem de Risco:}

Risco para Controle Ineficaz do Regime Terapêutico relacionado a déficit de conhecimento, história de drogadição e alcoolismo. O DE Risco para Controle Ineficaz do Regime Terapêutico, com base no referencial teórico das Necessidades Humanas Básicas (NHB) pertence ao Grupo de Necessidades Psicobiológicas, sendo que a necessidade alterada é a Educação para Saúde/Terapêutica 
e tem como definição: estado em que o indivíduo está em risco de apresentar dificuldades para integrar o programa de tratamento à vida diária. ${ }^{5,13}$

As intervenções de enfermagem prescritas foram: orientar para autocuidado, fornecer manual de orientações; explicar com clareza os aspectos do tratamento pós-transplante; monitorar aderência ao tratamento; orientar o paciente sobre os riscos do uso do álcool e drogas; obter um vínculo de confiança para que o paciente relate sua história de uso de álcool e drogas; atentar para comportamentos do paciente que possam indicar uso de álcool e drogas; incentivar o apoio da família para com o paciente; orientações de saúde: evitar prática de esportes agressivos que possam lesionar o enxerto, evitar tomar sol entre $10 \mathrm{~h}$ e $15 \mathrm{~h}$ e usar protetor solar com fator de proteção igual ou maior a 30, proibição do fumo (seus efeitos são potencializados pelos medicamentos), procurar manter atividade física regular, evitar alimentos ricos em sal, açúcares e gorduras e bebidas alcoólicas e orientar sobre a freqüência de consultas ambulatórias para controle., ${ }^{412}$

Destacamos outras intervenções de enfermagem, que orientamos para o DE Risco para Controle Ineficaz do Regime Terapêutico relacionado à complexidade do tratamento medicamentoso: orientar o paciente sobre a indicação, ação, dosagem, via de administração, horários, cuidados, armazenamento, interações e efeitos adversos de cada medicamento; avaliar a capacidade do paciente para auto-administrar os medicamentos; informar ao paciente o nome genérico de cada medicamento; informar ao paciente sobre as conseqüências de não tomar as medicações; orientar o paciente sobre sinais e sintomas de dosagem excessiva/reduzida da medicação; auxiliar o paciente a elaborar uma programação escrita sobre os medicamentos. ${ }^{4,12}$

Risco para infecção relacionado a procedimento invasivo, sorologia para Chagas positivo e trauma mecânico. O DE Risco para infecção, com base no referencial teórico das NHB, pertence ao Grupo de Necessidades Psicobiológicas, sendo que a necessidade alterada é a Segurança Física/Meio Ambiente e tem como definição: estado em que o indivíduo apresenta risco de ser invadido por organismos., ${ }^{4,5}$

As intervenções de enfermagem prescritas foram: observar sinais de infecção em ferida operatória; monitorar sinais vitais; orientar o paciente e a família sobre a técnica adequada de lavagem das mãos; orientar sobre higiene do ambiente; assegurar técnica adequada de cuidado com a ferida operatória; monitorar sinais sugestivos de infecção decorrente da doença de Chagas; manter curativos limpos; realizar troca de acessos venosos periféricos e curativos conforme orientação do controle de infecção; orientar paciente para que evite lugares fechados e aglomerados; ensinar o paciente sobre sinais e sintomas de infecção; ensinar o paciente e a família maneiras de evitar infecções e sobre o controle de imunizações/vacinas (orientar o paciente a não receber vacinas com vírus vivo atenuado e realizar ensino sobre sexualidade (uso de preservativos). ${ }^{4,12}$

\section{Diagnósticos de Enfermagem Reais:}

Volume excessivo de líquidos relacionado a mecanismos reguladores comprometidos, evidenciado por ganho de peso em curto período, alterações de pressão arterial e discreto edema de membros inferiores. O DE volume excessivo de líquidos, com base no referencial teórico das NHB pertence ao Grupo de Necessidades Psicobiológicas, sendo que a necessidade alterada é a hidratação e tem como definição: estado em que o indivíduo apresenta retenção aumentada de líquidos isotônicos. ${ }^{4,5}$

As intervenções de enfermagem prescritas foram: reforçar a importância da restrição de líquidos e sal; pesar o paciente diariamente; monitorar indicadores de sobrecarga (por exemplo: edema, ascite, distensão da veia do pescoço); realizar e registrar balanço hídrico (monitorar a ingesta e a eliminação); monitorar os sinais vitais; monitorar os níveis séricos e de osmolaridade urinária; avaliar a localização e a extensão do edema (se presente); administrar agentes farmacológicos para aumentar o débito urinário (quando adequado).,12

Integridade tissular prejudicada relacionado à alteração vascular, evidenciado pela presença de fístula arterio-venosa e circulação alterada. O Diagnóstico de Enfermagem Integridade Tissular Prejudicada, com base no referencial teórico das NHB pertence ao Grupo de Necessidades Psicobiológicas, sendo que a necessidade alterada é a Integridade Física e tem como definição: estado em que o indivíduo apresenta dano em mucosas, córnea, pele ou tecidos subcutâneos. ${ }^{4,5}$

As intervenções de enfermagem prescritas foram: monitorar diariamente o funcionamento da fístula $\mathrm{AV}$ através da palpação do frêmito, preservar membro com FAV (não realizar punções venosas periféricas, evitar deitar sobre o membro, dobrá-lo ou carregar peso e evitar medir a pressão arterial), ensinar o paciente a automonitorar sinais e sintomas indicativos da necessidade de tratamento médico (por exemplo: febre, sangramento, fístula coagulada, tromboflebite e pulsação irregular). ${ }^{4,12}$

Proteção ineficaz relacionada à terapia imunossupressora evidenciada por anemia e deficiência na imunidade. O Diagnóstico de Enfermagem Proteção Ineficaz, com base no referencial teórico das NHB, pertence ao Grupo de Necessidades Psicobiológicas, sendo que a necessidade alterada é a segurança física/meio ambiente e tem como definição: estado em que o indivíduo apresenta diminuição na capacidade de defender-se de causas externas ou internas, por doença ou lesão.,

As intervenções de enfermagem prescritas foram: verificar os sinais vitais diariamente; observar sinais de infecção; ensinar ao paciente e à família maneiras de evitar infecções: evitar contato com pessoas com doenças transmissíveis, evitar contato direto com animais domésticos, lavar bem frutas e verduras, usar água filtrada ou fervida, adequada higiene da pele e ambiente e ensinar sobre sinais e sintomas de infecção. ${ }^{4,12}$

Dor aguda relacionada a procedimento cirúrgico, evidenciada por relato verbal de dor em ferida operatória, expressão facial. Fator relacionado a procedimento cirúrgico. O Diagnóstico de Enfermagem Dor Aguda, com base no referencial teórico das NHB pertence ao Grupo de Necessidades Psicobiológicas, sendo que a necessidade alterada é a percepção dos órgãos dos sentidos e tem como definição: estado em que o indivíduo apresenta e relata sensação desconfortável, durante seis meses ou menos. ${ }^{4,13}$

As intervenções de enfermagem prescritas foram: solicitar para que o paciente comunique presença de dor; avaliar a eficácia da analgesia; observar indicadores não-verbais de desconforto (especialmente em pacientes incapazes de se comunicar com eficiência); determinar o impacto da experiência de dor sobre a qualidade de vida (por exemplo: sono, apetite, atividade); ensinar ao paciente o uso de técnicas nãofarmacológicas para alívio/controle da dor. ${ }^{12}$

Neste estudo de caso, os diagnósticos: Risco para Infecção e Risco 